\title{
Laccase-catalyzed polymerization of diaminobenzenesulfonic acid for pH-responsive colour-changing and conductive wool fabrics
}

Ting Zhang a , Rubing Bai ${ }^{\text {a }}$, Jinsong Shen ${ }^{\text {b,* }}$, Qiang Wang ${ }^{\text {a,** }}$, Ping Wang ${ }^{\text {a }}$, Jiugang Yuan ${ }^{\text {a }}$, Xuerong Fan ${ }^{\text {a }}$

${ }^{a}$ Key Laboratory of Science and Technology of Eco-Textile, Ministry of Education, Jiangnan University, Wuxi, 214122 Jiangsu, China

${ }^{\mathrm{b}}$ Textile Engineering and Materials (TEAM) Research Group, School of Design, De Montfort University, Leicester, LE1 9BH, UK

\section{Correspondence:}

*Prof. Jinsong Shen (jshen@dmu.ac.uk), Textile Engineering and Materials (TEAM) Research Group, School of Design, De Montfort University, Leicester, LE1 9BH, UK.

*** Prof. Qiang Wang (qiang_wang@163.com), Key Laboratory of Science and Technology of Eco-Textile, Ministry of Education, Jiangnan University, Wuxi, 214122 Jiangsu, China.

\begin{abstract}
In recent years, there has been an extensive interest in the research of smart fabrics and functional textiles. The present work has successfully developed the enzymatic approach for dyed wool fabrics in possession of special $\mathrm{pH}$-responsive colour-changing and conductive properties, via in-situ polymerization of 2,5-diaminobenzenesulfonic acid (DABSA) by laccase from Trametes versicolor. The enzymatically synthesized product, poly(2,5-diaminobenzenesulfonic acid) (PDABSA), were characterized by FT-IR, UV-Vis spectrophotometry and matrix assisted laser desorption ionization-time-of-flight mass
\end{abstract}


spectrometry (MALDI-TOF MS). The redox property and thermal stability of the polymer products were studied by cyclic voltammetry (CV) and TGA analysis, respectively. The results proved that the resulting polymer reached to $2 \mathrm{KDa}$ and showed strong $\mathrm{pH}$-dependence of UV-Vis absorption, electrochemical activity and high thermal stability. Utilizing the doping/dedoping process of PDABSA, the dyed wool fabrics were endowed with a pH-dependent redox potential. Furthermore, the dyed wool fabrics exhibited reversible colour change from dark purple at $\mathrm{pH} 1.8$ to yellowish-brown at $\mathrm{pH} 10.0$, indicating that the PDABSA showed unusual $\mathrm{pH}$-dependent colour-changing properties on dyed wool fabrics.

Keywords: wool, laccase, enzymatic polymerization, 2,5-diaminobenzenesulfonic acid, pH-responsive, conductive, colour-change

\section{Introduction}

With an increase in the demand of new wearable devices, the development of fibrous materials with new functions, such as electrical conductivity, has received great attention in material science. These materials not only play traditional roles of protection but also offer people more intelligent services. Polyaniline with its highly conjugated structure is typical of electrically conductive polymers due to its various oxidation states via special doping mechanism, chemical stability, remarkable electrical and optical properties. ${ }^{1}$ Many studies concerning the preparation and application of polyaniline-coated fabrics have been reported. It includes the preparation of conductive polyester ${ }^{2,3}$, wool $^{4}$ and cotton ${ }^{5}$ fabrics via chemical polymerization of polyaniline to form a layer of conductive polymer on the fabric surface. The 
potential application of polyaniline-coated fabric could be in many fields such as electrochromic displays $^{6,7}$, sensors ${ }^{8,9}$ and electromagnetic shielding ${ }^{10}$.

Polyaniline can exist in various oxidation forms. Among them, emeraldine base is the only one that is conductive after converting into emeraldine salt by doping. ${ }^{10,11}$ Doping to its conductive form can be achieved either through treatment with protonic acid, during which the number of electrons undergoes no change, or through treatment with oxidation agents by charge-transfer. ${ }^{12-15}$ Furthermore, the optical and electronic properties could be controlled reversibly by varying its doping level. ${ }^{13,16}$

Conductive polyaniline is commonly synthesized by oxidizing aniline monomer either chemically or electrochemically in acidic solutions. ${ }^{17-19}$ The polyaniline obtained has low solubility in common organic solvents and is difficult to be processed. 2,5-diaminobenzenesulfonic acid (DABSA) has an electron-withdrawing sulfonyl substituent and is of interest due to its unusual electroactive properties as well as improved processability. It also has better thermostability than the parent polyaniline ${ }^{20,21}$ and the potential application in rechargeable batteries with higher charge density ${ }^{22}$. Moreover, these traditional synthesis methods suffer from a number of limitations, such as the requirements of high amounts of oxidants, harsh reaction conditions, and also purification problems. ${ }^{23}$

Nowadays, biocatalysis has been recognized as an eco-friendly alternative to chemical synthesis of polyaniline due to its advantages of milder processing conditions such as neutral $\mathrm{pH}$ and lower temperature, as well as low waste and toxicity ${ }^{11,24}$, which meet the criteria of green chemistry $^{25}$. Laccases (EC.1.10.3.2), multicopper oxidoreductase, catalyze the oxidation of phenols and aromatic amines to their corresponding free radicals and further undergo 
non-enzymatic reactions to produce colored products. Some of these enzymatically synthesized colorants have been utilized in textile dyeing. ${ }^{26.27}$ The application of enzyme to in-situ dyeing provides an efficient alternative route to traditional textile coloration due to its high efficiency and eco-friendly nature as well as milder treatment conditions. DABSA, substituted aromatic amine, is a suitable substrate of laccase. ${ }^{28}$ A red sulfonic azoanthraquinone colorant synthesized by laccase-catalyzed oxidation of an aromatic amine compound exhibits low toxicity and good dyeing properties for nylon. ${ }^{29}$

It should be noted that colour-changing phenomenon of the polymers of phenols and aromatic amines had also gained more attention in the past years. Responsive colour-changing refers to the change of the colour in response to a wide variety of external stimuli, such as temperature ${ }^{30}$, light $^{31}$ and electricity ${ }^{32,33}$. It has been reported that the colour of polyaniline-coated fabric could be controlled reversibly between yellowish green and dark green by using electricity as a trigger to drive the colour change. ${ }^{34}$ The colour of coated cotton in the system of polyaniline/lignosulfonate (PANI-ES-LGS) transforms from emerald green to bluish violet under different concentrations of ammonia. ${ }^{35}$ Moreover, the colour of polyaniline-coated cotton in perfluorooctanesulfonate acid potassium salt (PFOS) templates could change from green to blue-purple after treatment with an alkaline gas. ${ }^{36}$

The present research was to investigate the feasibility of the enzymatic synthesis of functional polymers and their in-situ coloration of wool fabrics to achieve textile fabrics with colour change function and conductivity in responsive to $\mathrm{pH}$ change. Wool fibres are traditionally dyed with acid dyes at relatively high temperature up to a few hours, so that dye molecules can diffuse underneath of the lipid-covered cuticle layers of wool into the interior of 
the fibre. This enzyme-based eco-friendly approach has the potential advantage in not only saving time and energy from dyeing process but also providing unique functions to the wool fabrics. In the present paper, laccase-catalyzed polymerization of DABSA was performed in aqueous solution and then the colored polymers obtained were applied for dyeing wool fabrics to produce $\mathrm{pH}$-responsive conductive and colour-changing wool fabric, as shown in Scheme 1. Analytical characterizations of poly(2,5-diaminobenzenesulfonic acid) (PDABSA) were carried out by FT-IR, UV-Vis and MALDI-TOF MS. The electrochemical properties were studied by cyclic voltammetry (CV). Meanwhile, the colour reversibility and electrochemical properties of wool fabrics dyed by laccase with DABSA were assessed by means of $K / S$ values and CV.

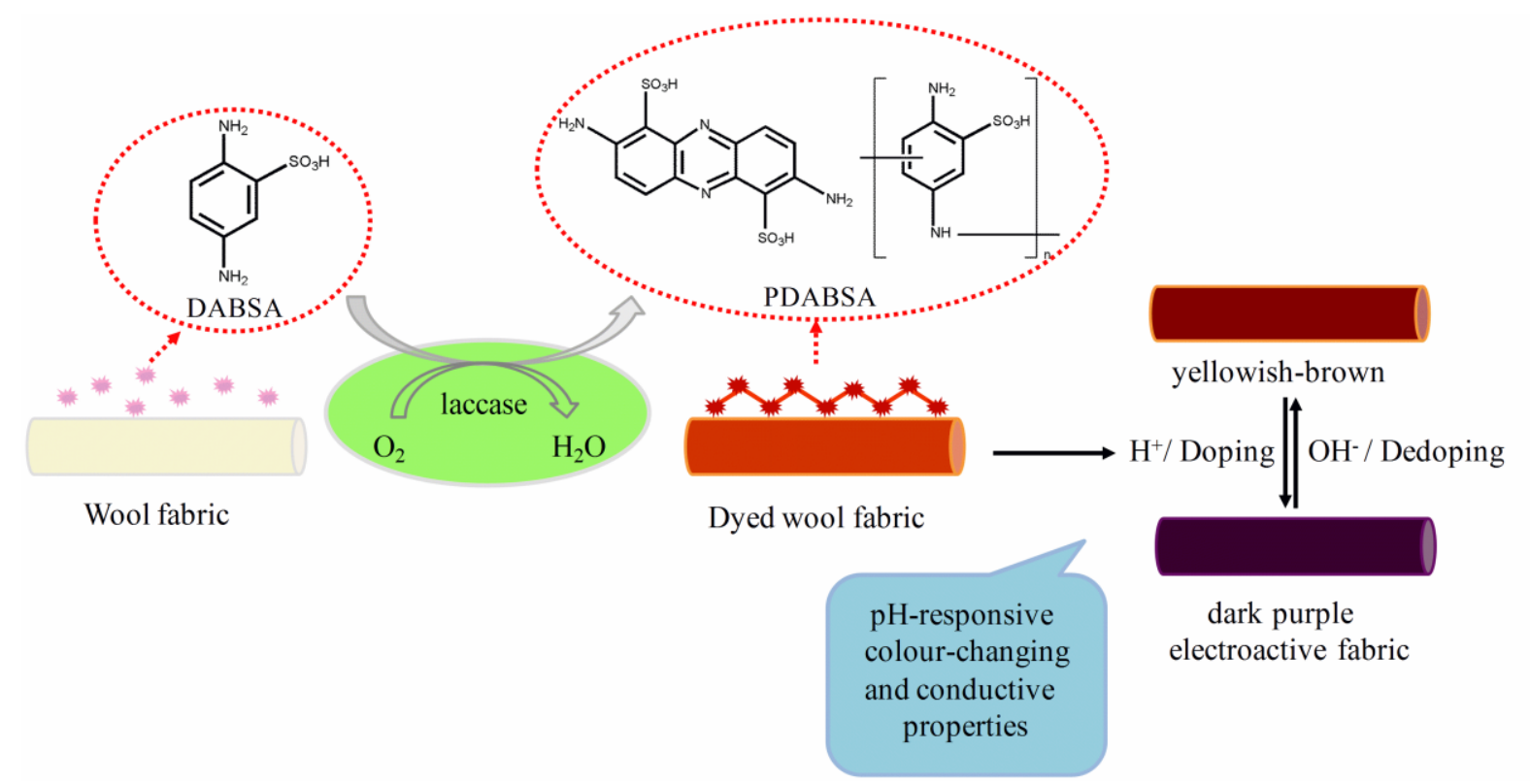

Scheme 1 Schematic illustration of preparation of pH-responsive colour-changing and conductive wool fabric via in-situ polymerization of 2,5-diaminobenzenesulfonic acid (DABSA) using laccase

\section{Materials and methods}

\subsection{Materials}


Laccases (EC.1.10.3.2) from Trametes versicolor with an activity of $0.5 \mathrm{U} / \mathrm{mg}$ and 2,5-diaminobenzenesulfonic acid (DABSA) with a purity of $97.0 \%$ were both purchased from Sigma-Aldrich (Shanghai, China) Trading Co., Ltd. Ultravon PL, a non-ionic surfactant, was supplied by Ciba Speciality Chemicals (Cheshire, UK). Nafion, produced by DuPont Company, was purchased from Sigma-Aldrich. The pre-scoured wool fabric used was a plain weave of 23 $\mu \mathrm{m}$ mean fiber diameter with 50 ends $\times 45$ picks per square inch and fabric weight of $183 \mathrm{~g} / \mathrm{m}^{2}$, which was kindly supplied by Drummond Parkland (Huddersfield, UK). All other reagents used in the experiment were of analytical grade and used as received.

\subsection{Laccase-catalyzed synthesis of poly(2,5-diaminobenzenesulfonic acid)}

Laccase-catalyzed polymerization of 2,5-diaminobenzenesulfonic acid (DABSA) was carried out by following the procedure below. DABSA $(0.2 \mathrm{~g})$ was dissolved in $100 \mathrm{~mL}$ of $0.2 \mathrm{M}$ acetate buffer set at $\mathrm{pH}$ 4. The reaction was initiated by the addition of $0.15 \mathrm{U} / \mathrm{mL}$ laccase. Synthesis process was performed in an Ahiba Nuance Top Speed II infrared dyer (Datacolor, Switzerland) with a rotation speed of $40 \mathrm{rpm}$ at $50^{\circ} \mathrm{C}$ for $24 \mathrm{~h}$. After the reaction, the polymer mixture was filtered and the filtered liquor was evaporated by rotary evaporator to obtain colored polymer. The final purified polymer was dried in vacuum at $60^{\circ} \mathrm{C}$ for $6 \mathrm{~h}$ for further characterization.

\subsection{Laccase-catalyzed dyeing of wool fabrics}

Woven wool fabric ( $2 \mathrm{~g}$ ) was incubated with $2 \%$ (owf) DABSA in $0.2 \mathrm{M}$ acetate buffer set at $\mathrm{pH} 4$ containing $0.1 \mathrm{U} / \mathrm{mL}$ laccase at a liquor-to-goods ratio of 50:1. Dyeing process was performed on an Ahiba Nuance Top Speed II infrared dyer (Datacolor, Switzerland) with a rotation speed of $40 \mathrm{rpm}$ at $50^{\circ} \mathrm{C}$ for $4 \mathrm{~h}$. After dyeing, wool fabric was rinsed with deionised 
water, then washed with $1 \mathrm{~g} / \mathrm{L}$ Ultravon PL at a liquor-to-goods ratio of 50:1 for $20 \mathrm{~min}$ at $80^{\circ} \mathrm{C}$ with the agitation set at $40 \mathrm{rpm}$. Finally, the dyed wool fabric was rinsed thoroughly with cold water and dried at room temperature.

To obtain the doped and dedoped form of the polymer coated on fabric, the same piece of dyed wool sample was treated with different $\mathrm{pH}$ solutions (adjusted by $1 \mathrm{M} \mathrm{H}_{2} \mathrm{SO}_{4}$ and $1 \mathrm{M}$ $\mathrm{NaOH}$ ) in the sequence of $\mathrm{pH} 1.8, \mathrm{pH} 10.0, \mathrm{pH} 1.8$ and $\mathrm{pH} 10.0$, respectively, at a liquor-to-goods ratio of 50:1 for $30 \mathrm{~min}$ at room temperature. After each treatment at different $\mathrm{pH}$ values, wool sample was rinsed with tap water and then dried at room temperature.

\subsection{FT-IR spectrum measurement}

FT-IR spectra of the DABSA and its polymer PDABSA were obtained in $\mathrm{KBr}$ pellets on a Nicolet iS10 infrared spectrophotometer (Thermo Nicolet, USA), using a conventional procedure. The spectra were recorded in the range of $4000-500 \mathrm{~cm}^{-1}$ at a resolution of $4 \mathrm{~cm}^{-1}$ and 32 scans per sample.

\subsection{UV-Vis spectrum analysis}

The polymerization of DABSA $(1 \mathrm{mM})$ catalyzed by $0.1 \mathrm{U} / \mathrm{mL}$ laccase in $0.2 \mathrm{M}$ acetate buffer ( $\mathrm{pH}$ 4) was performed in an Ahiba Nuance Top Speed II infrared dyer at $50^{\circ} \mathrm{C}$ for $4 \mathrm{~h}$ with a rotation speed of $40 \mathrm{rpm}$. The polymer solution diluted 10 times in $\mathrm{pH} 4$ buffer was set as stock solution. The $\mathrm{pH}$ range of stock solution was adjusted between 2 and 11.47 by $1 \mathrm{M} \mathrm{H}_{2} \mathrm{SO}_{4}$ and 1 $\mathrm{M} \mathrm{NaOH}$, respectively. UV-Vis spectra of each solution from different $\mathrm{pH}$ were monitored with a Jasco V-570 UV/Visible /NIR spectrophotometer, in the range of 300 - $700 \mathrm{~nm}$.

\subsection{Mass spectrometry}

Matrix assisted laser desorption ionization-time-of-flight mass spectrometry (MALDI-TOF 
MS) was performed to study the molecular weight of the enzymatically synthesized products. The analysis was conducted with an ultrafleXtreme MALDI-TOF/TOF mass spectrometer (Bruker Optics, USA). 2,5-dihydroxybenzoic acid (DHB) was used as a matrix. Samples were dissolved in deionised water $(4 \mathrm{mg} / \mathrm{mL})$ and then mixed with matrix at the 1:1 (vol:vol) ratio of the dissolved sample to DHB. $1 \mu \mathrm{L}$ of the mixture was placed on the target plate and air-dried.

\subsection{Thermogravimetric analysis}

Thermogravimetric analysis (TGA) test of laccase-catalyzed polymer was performed on a TGA/SDTA 851e thermogravimetric analyzer (Mettler Toledo, Switzerland). Samples were heated from $50^{\circ} \mathrm{C}$ to $600^{\circ} \mathrm{C}$ at a heating rate of $20^{\circ} \mathrm{C} / \mathrm{min}$ under nitrogen atmosphere.

\subsection{Electrochemical measurement}

The electroactive nature of PDABSA polymer and PDABSA dyed wool fabric were measured by cyclic voltammetry using a CHI 660D electrochemical workstation (CH Instruments Inc., Austin, USA). A three-electrode configuration cell was used with a glassy-carbon as working electrode, a platinum wire as counter electrode and a silver/silver chloride $(\mathrm{Ag} / \mathrm{AgCl})$ as reference electrode. Prior to the test of PDABSA, the glassy-carbon electrode was coated with a mixture of sample solution and Nafion emulsion, then air dried to obtain a film. Prior to the test of conductive wool sample, a small piece of the sample was fixed to the glassy-carbon electrode surface by drying with Nafion emulsion (1.5 wt $\%)$. The potential range was scanned from -0.1 to $+0.6 \mathrm{~V}$ at a scan rate of $50 \mathrm{mV} / \mathrm{s}$. All measurements were carried out in $\mathrm{pH} 4$ electrolyte $(0.2 \mathrm{M}$ acetate buffer $)$ at room temperature.

\subsection{Colorimetric analysis of enzymatically dyed wool fabrics}

Colorimetric parameters of dyed wool fabrics were performed on a Gretag Macbeth 
Color-Eye 7000A Spectrophotometer (Datacolor, New Windsor, USA) equipped with CIE D65/10 illuminant/observer. CIE L*a*b* system was used to define the colour of the fabrics. $\mathrm{L}^{*}$ (luminosity) values represent a scale of lightness with a value of 0 (black) to 100 (white). $\mathrm{a}^{*}$ (greenness-redness) values and $b^{*}$ (blueness-yellowness) values all range from -60 to 60 , in which positive values indicate redness and yellowness, while negative values indicate greenness and blueness, respectively. From the reflectance values of the dyed fabrics in the spectral range of $400-700 \mathrm{~nm}$, the colour depth $(K / S)$ was calculated by Kubelka-Munk equation ${ }^{37}$ :

$$
K / S=(1-R)^{2} / 2 R
$$

where $K$ is an adsorption coefficient, $S$ is a scattering coefficient and $R$ is the reflectance.

Meanwhile, color differences $(\Delta E)$ between the dyed wool fabric samples repeatedly doped or dedoped back at the same $\mathrm{pH} 1.8$ or 10.0 were also determined according to the CIE $\mathrm{L}^{*} \mathrm{a} * \mathrm{~b}^{*}$ color difference concept. ${ }^{38}$

\subsection{Colour fastness tests}

Colour fastness tests in terms of washing, rubbing and light fastness of enzymatically dyed wool fabrics were assessed. Washing fastness of dyed wool fabrics was assessed according to the standard method of ISO 105-C06 A1S : 2010. Rubbing fastness was assessed at dry and wet conditions according to the standard method: ISO 105-X12: 2001. Light fastness was obtained by following the standard method: ISO 105-B02: 2013 (xenon arc lamp).

\section{Results and discussion}

\subsection{FT-IR spectra analysis}

The FT-IR spectra of DABSA and its polymer (PDABSA) in a $\mathrm{KBr}$ pellets matrix are shown in Figure 1. FT-IR spectrum of DABSA (curve a) shows sharp peaks at $3428 \mathrm{~cm}^{-1}$ (with a 
doublet pattern at $3405 \mathrm{~cm}^{-1}$ ) and $3338 \mathrm{~cm}^{-1}$ which are the characteristic bands of amine stretching vibration. The broad peak at $2948 \mathrm{~cm}^{-1}$ is assigned to the sulfonic O-H bond stretching vibration. ${ }^{39}$ In the spectrum of PDABSA (curve b), the broad peak centered around $3447 \mathrm{~cm}^{-1}$ corresponds to -NH- stretching vibration. The peaks at $1560 \mathrm{~cm}^{-1}$ and $1490 \mathrm{~cm}^{-1}$ are assigned to a $\mathrm{C}=\mathrm{C}$ ring stretching in benzenoid and quinoid rings of polyaniline in doped form. ${ }^{40,41}$ There are also broader absorption bands at low energy regions due to its polymerization. Comparing to the monomer, PDABSA curve $\mathrm{b}$ showed that the number of vibration bands in the aromatic $\mathrm{C}-\mathrm{H}$ in-plane bending region $\left(1250-950 \mathrm{~cm}^{-1}\right)$ is lower, indicating the decrease in the ring $\mathrm{C}-\mathrm{H}$ bond due to laccase-catalyzed polymerization of DABSA.

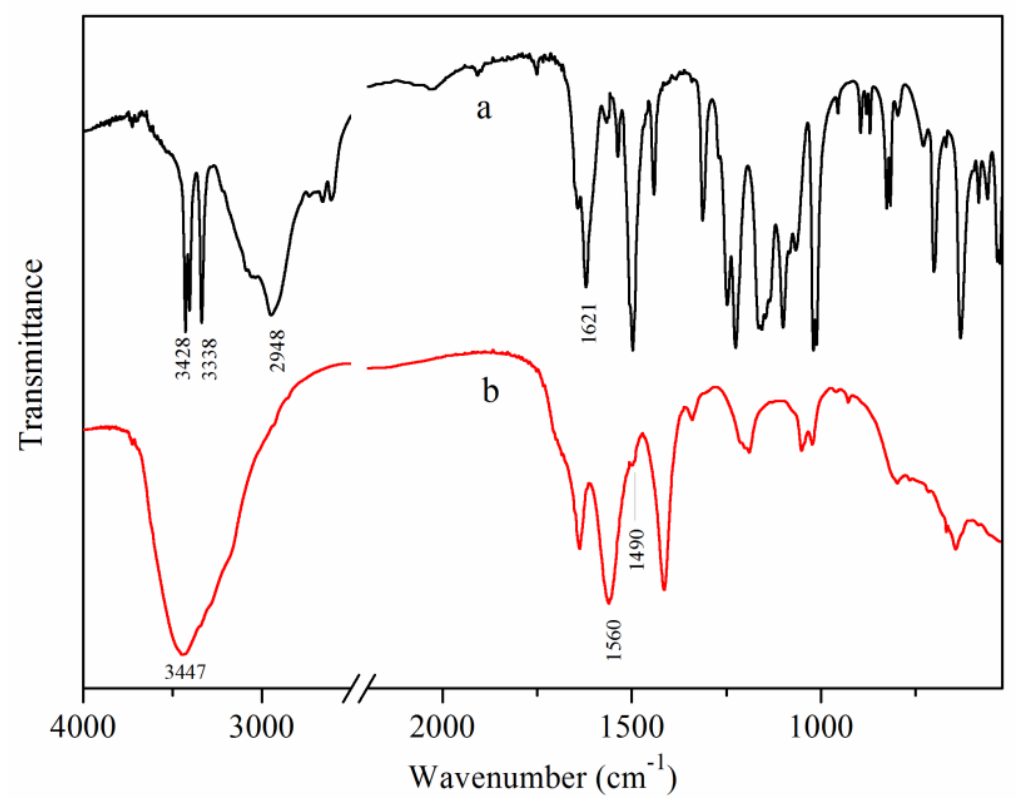

Figure 1 FT-IR spectra of DABSA (a) and PDABSA (b) in KBr pellets matrix

\subsection{MALDI-TOF MS analysis}

Analysis of the precise molecular mass of PDABSA by MALDI-TOF MS was undertaken to confirm the laccase-catalyzed polymerization and measure the extent of the reaction. As shown in Figure 2, a series of peak groups were detected in the mass spectrum of PDABSA, 
representing oligomers of different length. The main peaks of the consecutive groups, such as 933.3 Da, 1115.8 Da, 1297.9 Da, 1480.3 Da, 1663.5 Da and 1846.4 Da, were separated by 182.3 $\mathrm{Da}$, corresponding to the deprotonated molecular ion of DABSA, because the mass difference of 182.3 Da was in agreement with the molecular mass of monomer DABSA $\left(188.20 \mathrm{~g} \mathrm{~mol}^{-1}\right)$. The small difference between 182.3 Da and $188.20 \mathrm{~g} \mathrm{~mol}^{-1}$ of DABSA could be due to the detachment of hydrogen elements from sulfonic acid group, aromatic ring and amine group during its polymerization to PDABSA and laser ionization. The highest mass spectrum region close to $2 \mathrm{KDa}$ indicated that macromolecular colorants were obtained through laccase-catalyzed oxidation and the degree of polymerization almost reached to 11 . The mass differences (23 Da) of the peaks in each peak group were ascribed to the sodium element which is associated with sulfonic acid groups of polymer to form sodium salt and were shown as the raised peaks in a higher $m / z$ region.

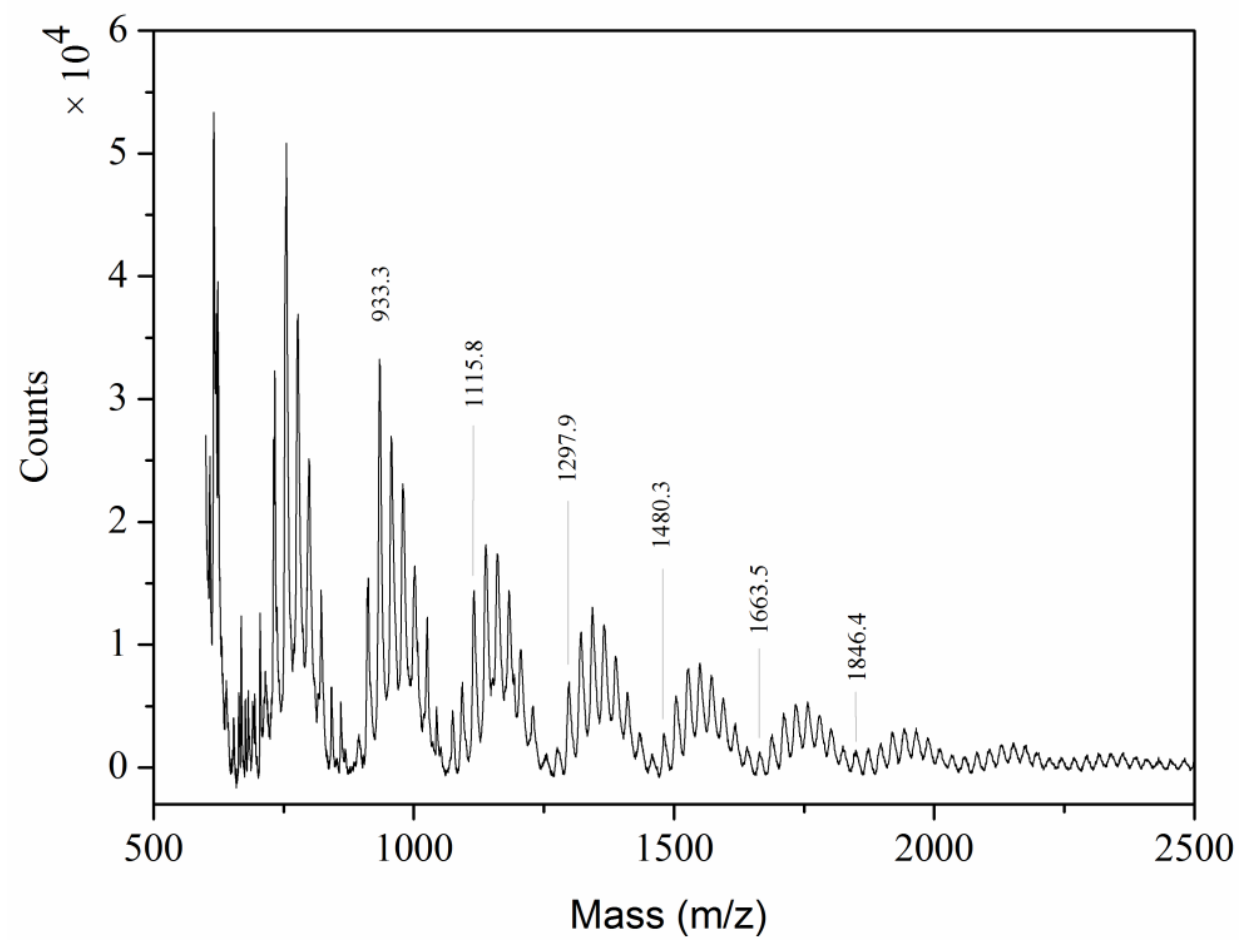

Figure 2 MALDI-TOF mass spectrum of PDABSA after 24 h reaction with laccase 


\subsection{Thermogravimetric analysis}

TGA and DTG analysis were carried out to investigate the decomposition patterns and thermal stability of the polymer produced from laccase-catalyzed polymerization, as shown in Figure 3. According to TGA data (Figure 3a), a small degree of decomposition of PDABSA occurred when the temperature started to increase. This might be because DABSA was polymerized by laccase to form the polymeric colorants with a range of molecular weights. This observation can be attributed to the decomposition of the PDABSA low molecular weight components. The major decomposition of PDABSA occurred from 350 to $443^{\circ} \mathrm{C}$, indicating a significant increase in thermal stability compared to that of DABSA from 290 to $332^{\circ} \mathrm{C}$. DABSA and PDABSA displayed weight retention of $61 \%$ and $85 \%$ at $332^{\circ} \mathrm{C}$, respectively, which might be related to the desulfonation from aromatic ring. According to DTG data (Figure 3b), the PDABSA showed the maximum rate of mass loss of 0.35 wt $\% /{ }^{\circ} \mathrm{C}$ at $415^{\circ} \mathrm{C}$ and less than $38 \%$ mass loss at $600^{\circ} \mathrm{C}$, while the DABSA showed the maximum rate of mass loss of $1.13 \mathrm{wt} \% /{ }^{\circ} \mathrm{C}$ at $302^{\circ} \mathrm{C}$ and almost $53 \%$ mass loss at $600^{\circ} \mathrm{C}$, which is probably due to the decomposition of the polymer backbone. All the results from TGA and DTG analysis confirmed higher thermal stability of PDADSA. 

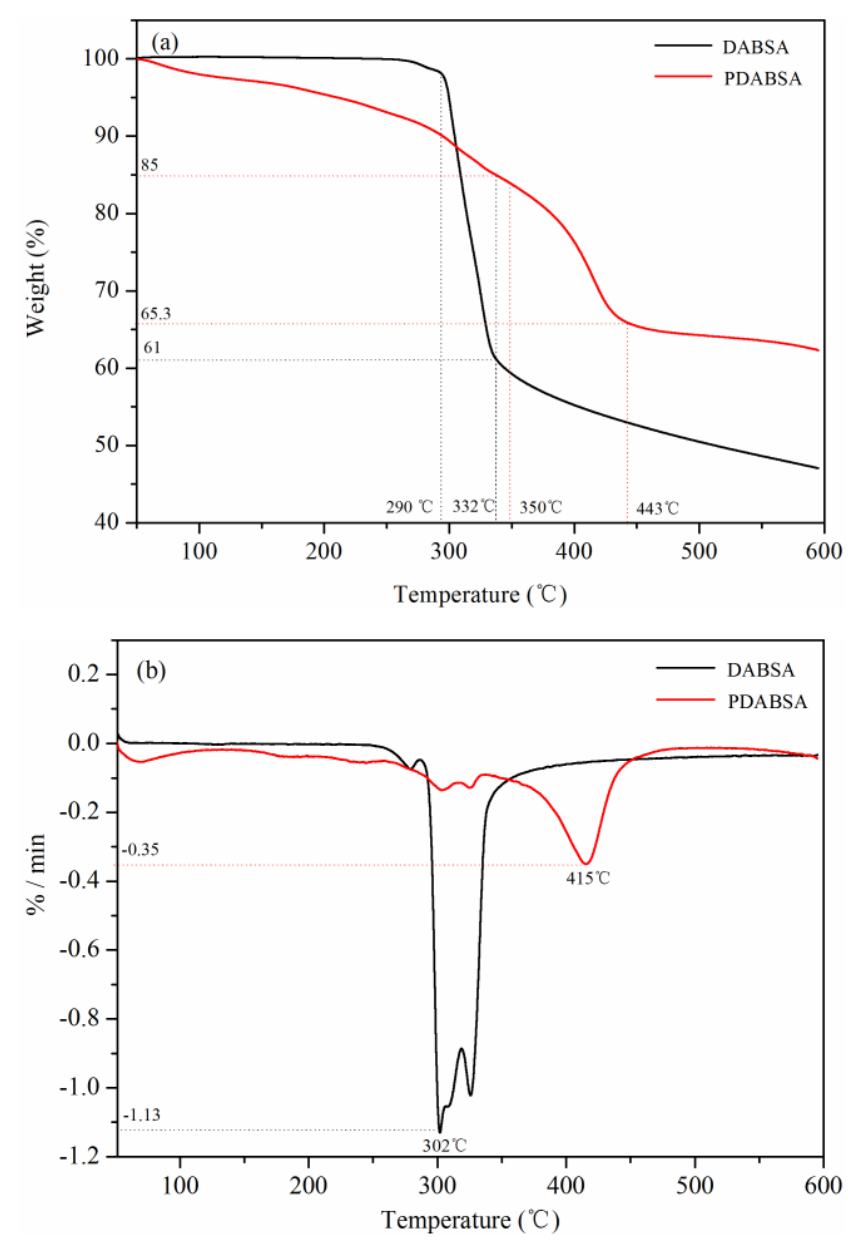

Figure 3 TGA (a) and DTG (b) curves of DABSA and PDABSA synthesized by laccase

\subsection{Electrochemical properties of the PDABSA}

The electrochemical properties of enzymatically synthesized polymers were investigated by cyclic voltammetry $(\mathrm{CV})$, as shown in Figure 4 . The $\mathrm{CV}$ of the monomer DABSA (curve a) presented an oxidation potential of $0.48 \mathrm{mV}$ with respect to $\mathrm{Ag} / \mathrm{AgCl}$ at a scan rate of $50 \mathrm{mV} / \mathrm{s}$. In contrast to curve a, a new cathodic peak at $0.17 \mathrm{mV}$ and a new anodic peak at $0.22 \mathrm{mV}$ appeared in curve $\mathrm{b}$ for PDABSA, which corresponded to reduction potential and oxidation potential, respectively. The result indicated that the polymer possessed different redox properties from that of the monomer. This pair of redox peaks confirmed that PDABSA synthesized by laccase had relatively high electrochemical activity, implying its potential applications in the 
fields of biosensor and electronic devices.

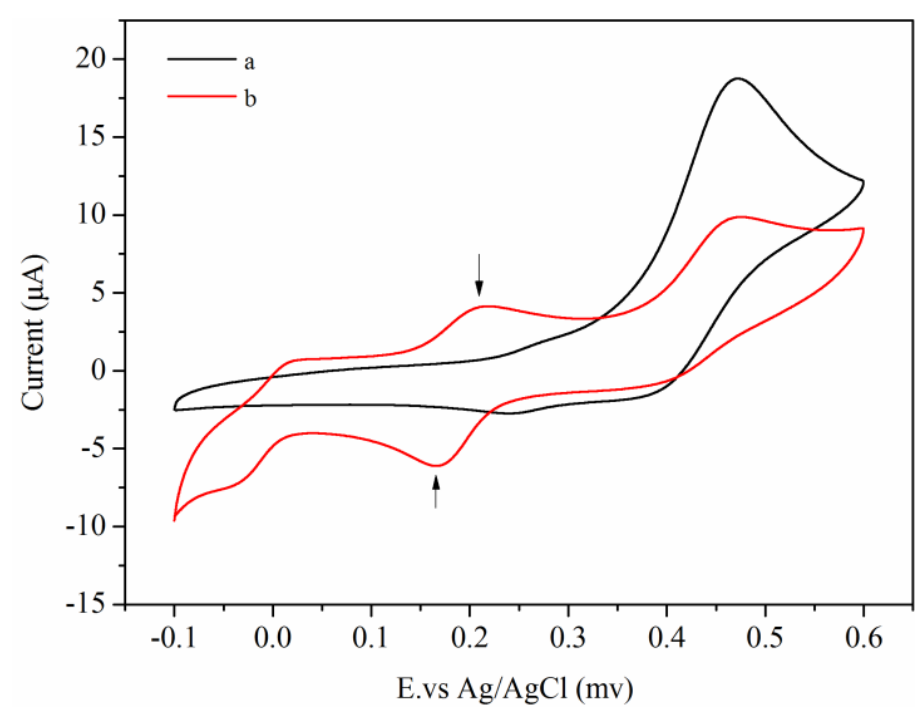

Figure 4 Cyclic voltammograms of DABSA (a) and PDABSA (b) recorded in pH 4 electrolyte $(0.2 \mathrm{M}$ acetate buffer) at a scan rate of $50 \mathrm{mV} / \mathrm{s}$. Arrows indicate a pair of redox peaks of PDABSA polymer

\subsection{UV-Vis spectra analysis}

In order to reveal the effect of $\mathrm{pH}$ on the UV-Vis absorption of polymer solution, the $\mathrm{UV}-\mathrm{Vis}$ spectra of polymer solution at various $\mathrm{pH}$ values (2 to11.47) were recorded as shown in Figure 5. It can be observed that the absorption characteristics underwent significant changes upon the $\mathrm{pH}$ of polymer solution adjusted from 2 to 11.47. The maximum absorptions around $350 \mathrm{~nm}$ and $547 \mathrm{~nm}$ decreased gradually and disappeared as $\mathrm{pH}$ increased, while a strong peak around $465 \mathrm{~nm}$ appeared with increasing $\mathrm{pH}$. These variations of absorbance can be ascribed to the facts that aqueous solution of PDABSA can be converted between its $\mathrm{H}^{+}$-doped and dedoped form by treating with protonic acids, and its optical properties could be controlled reversibly as well by varying its doping level. ${ }^{13,16}$ Below $\mathrm{pH} 4.5$, the PDABSA was in its doped form as reflected in the existence of polaron absorption band at about $350 \mathrm{~nm}$ and $547 \mathrm{~nm}$, while for $\mathrm{pH}$ values higher than 4.5 the absorption band at $465 \mathrm{~nm}$ was assigned to the characteristic 
absorption band of conjugated polymer. In addition, as seen from the inset picture in Figure 5, aqueous solution of PDABSA showed the transition of the colour from red to yellow when the $\mathrm{pH}$ changed from 2 to 11.47 . The differences in colour appearance indicated that different compounds were obtained depending on the $\mathrm{pH}$ value. Wool fabrics dyed with DABSA in the presence of laccase also displayed the maximum absorption at $580 \mathrm{~nm}$ and $460 \mathrm{~nm}$ after post-treatments at $\mathrm{pH} 1.8$ and $\mathrm{pH} 10.0$ respectively, which will be discussed in the later section.

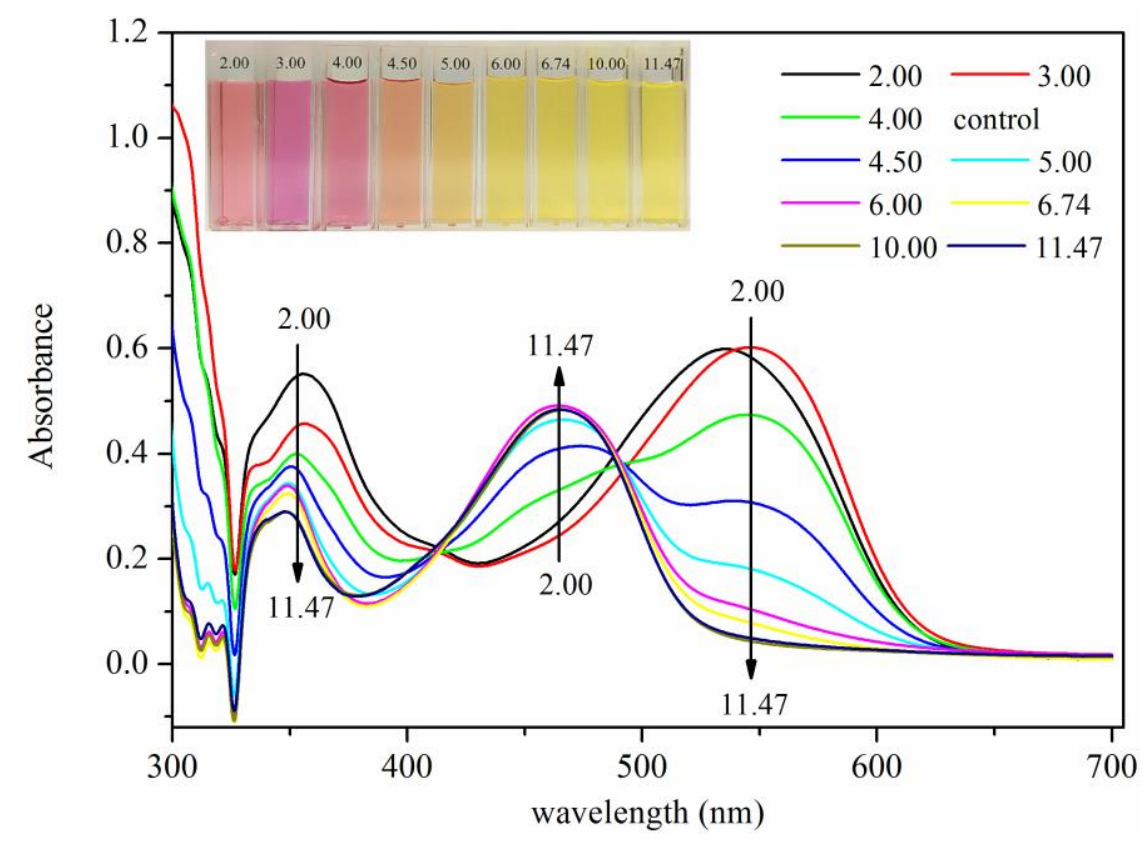

Figure 5 UV-Vis spectra of PDABSA in the solutions of various $\mathrm{pH}$ values and the photograph of colour appearance of polymer at various $\mathrm{pH}$ values (inset)

\subsection{Electrochemical characteristics and colour reversibility of enzymatically dyed wool}

\section{fabrics}

Wool fabrics were dyed in-situ by laccase-catalyzed polymerization of DABSA. The electroactivity of dyed wool fabrics through doping with $\mathrm{H}_{2} \mathrm{SO}_{4}$ and dedoping with $\mathrm{NaOH}$ was assessed by cyclic voltammetry (CV), as shown in Figure 6. There were no redox peaks detected in $\mathrm{CV}$ of original wool and the dyed wool sample post-treated with $\mathrm{pH} 10.0$ solution. This indicated that undyed wool and dedoped PDABSA-coated wool fabrics do not have conductive 
property. However, one oxidation peak around $0.53 \mathrm{~V}$ and another reduction peak (marked in the figure) at $0.45 \mathrm{~V}$ appeared in $\mathrm{CV}$ of dyed wool sample after doping treatment at $\mathrm{pH} 1.8$. This might be due to the formation of the polaron structure of PDABSA, resulting in its conductivity. This reversible change through doping treatment at between $\mathrm{pH} 1.8$ and 10.0 demonstrated that wool fabrics dyed with PDABSA solution could respond to external stimulus and showed a $\mathrm{pH}$-dependent oxidation potential. These can be ascribed to the fact that polyaniline can be doped to its conductive form with the number of $\pi$-electrons unchanging via protonation of its imine sites through exposure to a protonic acid solution. ${ }^{15,16}$

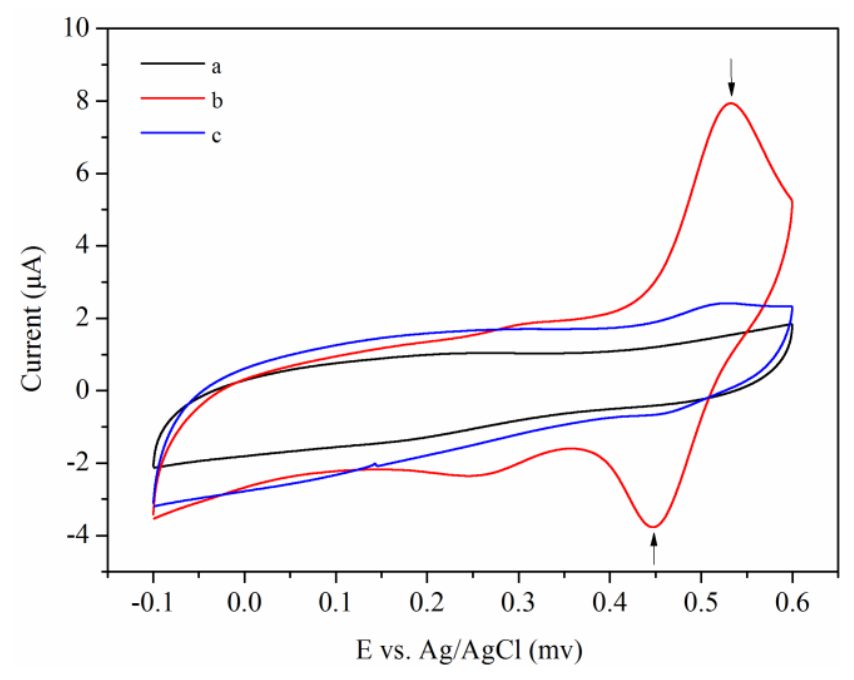

Figure 6 Cyclic voltammograms of original wool sample (a), dyed wool sample treated with $\mathrm{pH}$ 1.8 solution (b) and dyed wool sample treated with $\mathrm{pH} 10.0$ solution (c) recorded in $\mathrm{pH} 4$ electrolyte $(0.2 \mathrm{M}$ acetate buffer $)$ at a scan rate of $50 \mathrm{mV} / \mathrm{s}$

The same piece of dyed wool sample was treated with solution set at different $\mathrm{pH}$ values.

Figure 7 shows $K / S$ data and photographs of enzymatically dyed wool fabrics with colour reversibility. It was observed that enzymatically dyed wool fabrics post-treated with $\mathrm{pH} 1.8$ and $\mathrm{pH} 10.0$ solutions showed the maximum absorbance at around $560 \mathrm{~nm}$ and $480 \mathrm{~nm}$ respectively. Upon adjusting the $\mathrm{pH}$ from 10.0 to 1.8 , the peak of the maximum absorbance shifted from 480 
$\mathrm{nm}$ to $560 \mathrm{~nm}$. This change in colour was reversible as the maximum absorbance at $560 \mathrm{~nm}$ was shifted back to $480 \mathrm{~nm}$ again after treatment with $\mathrm{pH} 10.0$ solution for $30 \mathrm{~min}$. Meanwhile, the dyed wool fabrics exhibited reversible colour conversion from dark purple at $\mathrm{pH} 1.8$ condition to yellowish-brown at pH 10.0 condition, as shown in Figure 7(b). Moreover, the dyed wool fabrics treated with the same $\mathrm{pH}$ have matched $K / S$ depths under maximum absorption and indices of $L^{*}$, $a^{*}$ and $b^{*}$, as presented in Table 1 . These results were consistent with the results of $K / S$ data analysis. The results revealed that the peak at $580 \mathrm{~nm}$ can be assigned to the doped form of the polymer, due to the doping effect by proton on quinoid unit of the polymer.

All the results confirmed the $\mathrm{pH}-$-responsive colour-changing and conductive properties of PDABSA-coated wool fabrics and their potential applications in the fields of colour-changeable textiles and flexible electronic devices. 


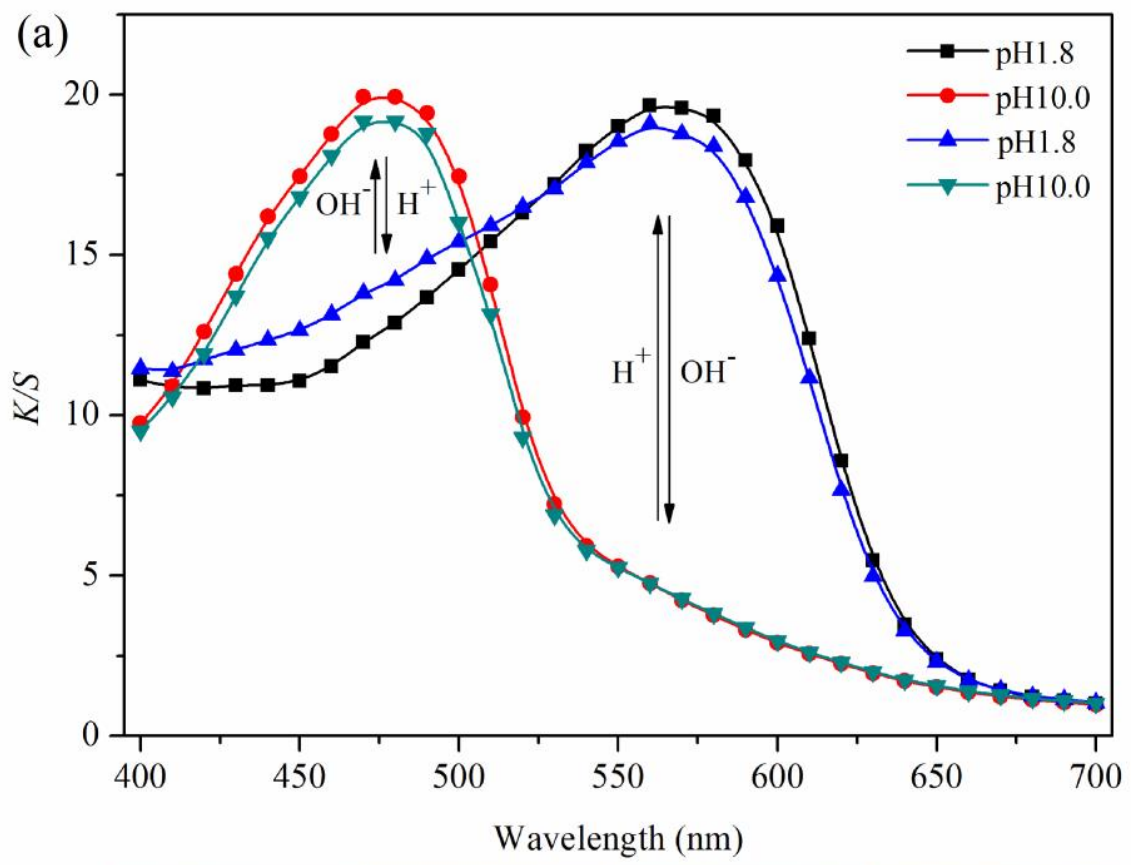

(b)

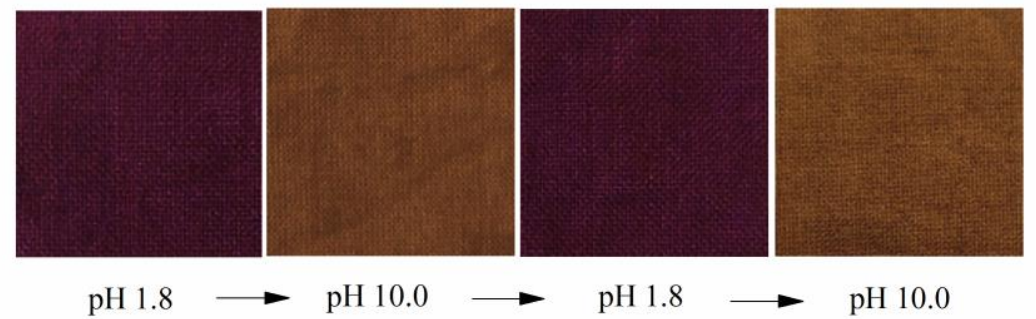

Figure $7 \mathrm{~K} / \mathrm{S}$ data (a) and photographs (b) of wool fabrics enzymatically dyed with PDABSA after doping treatment with $\mathrm{H}_{2} \mathrm{SO}_{4}$ at $\mathrm{pH} 1.8$ and dedoping with $\mathrm{NaOH}$ at $\mathrm{pH} 10.0$

Table 1 Colour parameters $\left(L^{*}, a^{*}, b^{*}\right.$ and $\left.K / S\right)$ of enzymatically dyed wool samples post-treated at different $\mathrm{pH}$ and their colour difference $(\Delta E)$ between the samples repeatedly doped or dedoped back at same $\mathrm{pH} 1.8$ or 10.0

\begin{tabular}{|c|c|c|c|c|c|}
\hline $\mathrm{pH}$ & $L^{*}$ & $a^{*}$ & $b^{*}$ & $\Delta E$ & $K / S$ \\
\hline${ }_{\Downarrow} .8$ & 21.5 & 14.4 & -3.8 & - & $19.7(560 \mathrm{~nm})$ \\
\hline $\begin{array}{c}10.0 \\
\Downarrow\end{array}$ & 34.8 & 17.8 & 26.4 & - & $19.9(480 \mathrm{~nm})$ \\
\hline${ }_{\Downarrow}^{1.8}$ & 21.7 & 15.0 & -1.1 & 2.8 & $19.1(560 \mathrm{~nm})$ \\
\hline 10.0 & 34.0 & 17.1 & 25.4 & 1.5 & $19.2(480 \mathrm{~nm})$ \\
\hline
\end{tabular}

\subsection{Colour fastness analysis}

The colour fastness of the wool fabrics enzymatically dyed and subsequently treated with 
different $\mathrm{pH}$ was evaluated, and their results are presented in Table 2. The multi-fiber strips consisting of six different fibers: wool, acrylic, polyester, nylon, cotton, and acetate were used as reference fabric to evaluate the colour staining. For the washing fastness, the colour change results of dyed wool fabrics post-treated at $\mathrm{pH} 1.8$ had better grade of 4 than that of dyed wool fabrics post-treated at $\mathrm{pH} 10.0$ (grade 3), indicating that biopolymers had a stronger affinity on wool fabric especially after protonic acid treatment under low $\mathrm{pH}$ condition. Most of the ratings of colour staining achieved the highest grade of 5, except for the cotton fabric which had the grade of $4 / 5$, showing that nearly no colorants stained on reference fabric surface. For the rubbing fastness, all dyed wool fabrics had good colour resistance against rubbing under dry conditions, while the wet rubbing fastness obtained was not satisfactory in the range of $2 / 3$ to 3 . For light fastness, the dyed wool fabrics post-treated with $\mathrm{pH} 1.8$ and $\mathrm{pH} 10.0$ had ratings of 3 and $3 / 4$, respectively. That might be due to a larger amount of polymeric dyes fixed on the surface of fabrics, resulting in poor colour fastness to rubbing. Polymeric dyes might not be stable under UV-light. Therefore, colour fastness to rubbing and light needs to be improved by further finishing process with dye fixation and UV-light protection agents to protect polymeric dyes on the fabric surface.

Table 2 Colour fastness of enzymatically dyed wool fabrics post-treated with different $\mathrm{pH} 1.8$ and 10.0 respectively

\begin{tabular}{|c|c|c|c|c|c|c|c|c|c|c|}
\hline \multirow{3}{*}{ Samples } & \multicolumn{7}{|c|}{ Washing Fastness } & \multirow{2}{*}{\multicolumn{2}{|c|}{$\begin{array}{l}\text { Rubbing } \\
\text { Fastness }\end{array}$}} & \multirow{3}{*}{$\begin{array}{c}\text { Light } \\
\text { Fastness }\end{array}$} \\
\hline & \multirow{2}{*}{ Fading } & \multicolumn{6}{|c|}{ Staining } & & & \\
\hline & & wool & acrylic & polyester & nylon & Cotton & acetate & Dry & Wet & \\
\hline Treated with $\mathrm{pH} 1.8$ & 4 & 5 & 5 & 5 & 5 & $4 / 5$ & 5 & 4 & 3 & 3 \\
\hline Treated with $\mathrm{pH} 10.0$ & 3 & 5 & 5 & 5 & 5 & $4 / 5$ & 5 & 4 & $2 / 3$ & $3 / 4$ \\
\hline
\end{tabular}




\section{Conclusions}

A conductive polyaniline has been successfully synthesized via laccase-catalyzed polymerization of 2,5-diaminobenzenesulfonic acid (DABSA) and subsequent doping with protonic acid. The polymer products (PDABSA) were characterized by the FT-IR, UV-Vis and CV analyses, along with MALDI-TOF MS analysis. The results showed that the colour and conductivity of the polymer were responsive to the $\mathrm{pH}$ change. The $\mathrm{pH}$-responsive colored and conductive polymer obtained could be directly applied for simultaneous dyeing and functional finishing of wool fabrics via in-situ enzymatic polymerization. This enzymatically dyed wool fabrics demonstrated good dyeing properties and electro-optical properties under different $\mathrm{pH}$ values. Also, the change of colour from dark purple to yellowish-brown was visually perceptible. Dyed wool fabrics showed good colour fastness to washing and dry rubbing but unsatisfied wet rubbing and light fastness. Moreover, PDABSA could endow the dyed wool fabrics with a $\mathrm{pH}$-dependent redox potential. The incorporation of conductive polymers with textile materials can be further exploited for their potential applications as prospective conductive materials for flexible electronic devices and colour-changing textiles. The laccase-catalyzed synthesis of self-doped polyaniline proposed here will open a path toward novel and environmental friendly production of conductive textile materials.

\section{Acknowledgement}

This work was financially supported by National Natural Science Foundation of China (51673087 and 21274055), Fundamental Research Funds for the Central Universities (JUSRP51717A), The National Key Research and Development Program of China (2017YFB0309203) and Program for Changjiang Scholars and Innovative Research Teams at the 
universities (IRT_15R26).

\section{References}

1. Otrokhov G V, Morozova O V, Vasil'eva I S, et al. Biocatalytic synthesis of conducting polymers and prospects for its application. Biochemistry (Moscow), 2013, 78(13): 1539-1553.

2. Molina J, Fernández J, Del Rio A I, et al. Electrochemical synthesis of polyaniline on conducting fabrics of polyester covered with polypyrrole/ $/ \mathrm{PW}_{12} \mathrm{O}_{40}{ }^{3-}$. Chemical and electrochemical characterization. Synthetic Metals, 2011, 161(11): 953-963.

3. Molina J, Esteves M F, Fernández J, et al. Polyaniline coated conducting fabrics. Chemical and electrochemical characterization. European Polymer Journal, 2011, 47(10): 2003-2015.

4. Hirase R, Shikata T, Shirai M. Selective formation of polyaniline on wool by chemical polymerization, using potassium iodate. Synth Met 2004; 146(1):73-7.

5. Onar N, Akşit A C, Ebeoglugil M F, et al. Structural, electrical, and electromagnetic properties of cotton fabrics coated with polyaniline and polypyrrole. Journal of applied polymer science, 2009, 114(4): 2003-2010.

6. Kitani A, Yano J, Sasaki K. ECD materials for the three primary colors developed by polyanilines. Journal of electroanalytical chemistry and interfacial electrochemistry, 1986, 209(1): 227-232.

7. Yang C H, Wang T L, Shieh Y T. Molecular assembled crosslinked self-doped polyaniline nano-thin films in application of electrochromic devices. Electrochemistry Communications, 2009, 11(2): 335-338.

8. Xie D, Jiang Y, Pan W, et al. Fabrication and characterization of polyaniline-based gas sensor by ultra-thin film technology. Sensors and Actuators B: Chemical, 2002, 81(2): 158-164.

9. Gerard M, Chaubey A, Malhotra B D. Application of conducting polymers to biosensors. Biosensors and bioelectronics, 2002, 17(5): 345-359.

10. Dhawan S K, Singh N, Venkatachalam S. Shielding behaviour of conducting polymer-coated fabrics in X-band, W-band and radio frequency range. Synth Met, 2002, 129(3):261-267.

11. Karamyshev A V, Shleev S V, Koroleva O V, et al. Laccase-catalyzed synthesis of conducting polyaniline. Enzyme and Microbial Technology, 2003, 33(5): 556-564. 
12. Macdiarmid A G, Chiang J C, Halpern M, et al. "Polyaniline": interconversion of metallic and insulating forms. Molecular Crystals and Liquid Crystals, 1985, 121(1-4): 173-180.

13. MacDiarmid A G, Chiang J C, Richter A F, et al. Polyaniline: a new concept in conducting polymers. Synthetic Metals, 1987, 18(1): 285-290.

14. Chen S A, Hwang G W. Water-soluble self-acid-doped conducting polyaniline: structure and properties. Journal of the American Chemical Society, 1995, 117(40): 10055-10062.

15. Lebedev M Y, Lauritzen M V, Curzon A E, et al. Solvato-controlled doping of conducting polymers. Chemistry of materials, 1998, 10(1): 156-163.

16. Nguyen M T, Kasai P, Miller J L, et al. Synthesis and properties of novel water-soluble conducting polyaniline copolymers. Macromolecules, 1994, 27(13): 3625-3631.

17. Liu G, Freund M S. New approach for the controlled cross-linking of polyaniline: synthesis and characterization. Macromolecules, 1997, 30(19): 5660-5665.

18. Verghese M M, Ramanathan K, Ashraf S M, et al. Electrochemical growth of polyaniline in porous sol-gel films. Chemistry of materials, 1996, 8(4): 822-824.

19. Venancio E C, Wang P C, MacDiarmid A G. The azanes: A class of material incorporating nano/micro self-assembled hollow spheres obtained by aqueous oxidative polymerization of aniline. Synthetic metals, 2006, 156(5): 357-369.

20. Tsai T C, Tree D A, High M S. Degradation kinetics of polyaniline base and sulfonated polyaniline. Industrial \& engineering chemistry research, 1994, 33(11): 2600-2606.

21. Neoh K G, Kang E T, Tan K L. Degradation behavior of polyanilines with different modes of doping. Polymer degradation and stability, 1994, 43(1): 141-147.

22. Barbero C, Miras M C, Schnyder B, et al. Sulfonated polyaniline films as cation insertion electrodes for battery applications. Part 1: Structural and electrochemical characterization. Journal of Materials Chemistry, 1994, 4(12): 1775-1783.

23. Venancio E C, Wang P C, MacDiarmid A G. The azanes: A class of material incorporating nano/micro self-assembled hollow spheres obtained by aqueous oxidative polymerization of aniline. Synthetic metals, 2006, 156(5): 357-369.

24. Liu W, Kumar J, Tripathy S, et al. Enzymatic synthesis of conducting polyaniline in micelle solutions. Langmuir, 2002, 18(25): 9696-9704.

25. Clark J H. Green chemistry: challenges and opportunities. Green Chemistry, 1999, 1(1): 1-8. 
26. Kudanga T, Nyanhongo G S, Guebitz G M, et al. Potential applications of laccase-mediated coupling and grafting reactions: a review. Enzyme and microbial technology, 2011, 48(3): 195-208.

27. Polak J, Jarosz-Wilkolazka A. Fungal laccases as green catalysts for dye synthesis. Process Biochemistry, 2012, 47(9): 1295-1307.

28. Sousa A C, Oliveira M C, Martins L O, et al. Towards the rational biosynthesis of substituted phenazines and phenoxazinones by laccases. Green Chemistry, 2014, 16(9): 4127-4136.

29. Enaud E, Trovaslet M, Bruyneel F, et al. A novel azoanthraquinone dye made through innovative enzymatic process. Dyes and Pigments, 2010, 85(3): 99-108.

30. Christie R M, Bryant I D. An evaluation of thermochromic prints based on microencapsulated liquid crystals using variable temperature colour measurement. Coloration technology, 2005, 121(4): 187-192.

31. Little A F, Christie R M. Textile applications of photochromic dyes. Part 1: establishment of a methodology for evaluation of photochromic textiles using traditional colour measurement instrumentation. Coloration Technology, 2010, 126(3): 157-163.

32. Yang C H, Wang T L, Shieh Y T. Molecular assembled crosslinked self-doped polyaniline nano-thin films in application of electrochromic devices. Electrochemistry Communications, 2009, 11(2): 335-338.

33. Peng H, Sun X, Cai F, et al. Electrochromatic carbon nanotube/polydiacetylene nanocomposite fibres. Nature Nanotechnology, 2009, 4(11): 738-741.

34. Gauvreau B, Guo N, Schicker K, et al. Color-changing and color-tunable photonic bandgap fiber textiles. Optics express, 2008, 16(20): 15677-15693.

35. Zhang Y, Dong A, Fan X, et al. Laccase-catalyzed synthesis of conducting polyaniline-lignosulfonate composite. Journal of Applied Polymer Science, 2016, 133(5): 42941. 36. Zhang Y, Fan X, Wang Q, et al. Preparation of functionalized cotton based on laccase-catalyzed synthesis of polyaniline in perfluorooctanesulfonate acid potassium salt (PFOS) template. RSC Advances, 2016, 6(54): 49272-49280.

37. McDonald R. Industrial Pass/Fail Colour Matching. Part III - Development of a Pass/Fail Formula for use with Instrumental Measurement of Colour Difference. Journal of the Society of Dyers and Colourists, 1980, 96(9): 486-497. 
38. Harold R W. Textiles: Appearance Analysis and Shade Sorting. Textile Chemist \& Colorist, 1987, 19(12): 23-31.

39. Alva K S, Kumar J, Marx K A, et al. Enzymatic synthesis and characterization of a novel water-soluble polyaniline: poly (2, 5-diaminobenzenesulfonate). Macromolecules, 1997, 30(14): 4024-4029.

40. Ghosh P, Siddhanta S K, Chakrabarti A. Characterization of poly (vinyl pyrrolidone) modified polyaniline prepared in stable aqueous medium. European Polymer Journal, 1999, 35(4): 699-710.

41. Mav I, Zigon M. Chemical copolymerization of aniline derivatives: Preparation of fully substituted PANI. Synthetic metals, 2001, 119(1-3): 145-146. 